\title{
A sociologia do trabal ho e a sociologia do futebol: uma análise da flexibilização das relações de trabalho no futebol brasileiro (2001-2003)*
}

\author{
Francisco Xavier Freire Rodrigues ${ }^{* *}$
}

\begin{abstract}
R esumo: O ensaio analisa as recentes transformaçães no mundo do trabalho do futebol brasileiro, estabelecendb um diálogo entre a sociologia do trabalho e a sociologia do futebol. Trata-se de una investigação sobre o processo de flexibilização das relaçães de trabalho no futebol, analisandb alguns de seus impactos no futebol gaúcho, no períodb de 2001 a 2003. A flexibilidade db trabalho no futebol teve início com a Iei n. 9.615/03/1998, que determinou o fim do passe. A maioria dos jogadbres considera positivas a modemização das leis trabalhistas e a flexibilização das relaçães de trabalho no futebol. Os resultadbs apontam que as principais opiniões scbre o fim do passe são: (a) liberdade de trabalho; (b) fim da garantia no trabalho e desemprego, e (c) benefício que alcança apenas as jogadbres famosos. Para os profissionais e juniores, o fim do passe significa liberdade de trabalho; para os juvenis, representa benefícios apenas para os jogadores famosos.
\end{abstract}

Palavr as-chave: sociologia do trabalho, sociologia do futebol, flexibilidade.

Introdução

Este trabal ho analisa as recentes transformações no mundo do trabalho do futebol brasileiro, estabelecendo um diálogo entre a sociologia do trabal ho e a sociologia do futebol. Investiga o processo de flexibilização das relações de trabalho no futebol, identificando alguns de seus impactos no futebol gaúcho (2001-2003), no SC Internacional. A flexibilidade do trabalhono futebol teve início com a entrada em vigor da L ei $n$-9.615/03/1998, que determinou o fim do passe. Por passe, entende-se o vínculo jurídico entre atleta e clube, através do qual 0 atleta é patrimônio do clube e não um simples empregado.

\footnotetext{
* Texto apresentado na comissão de trabalho A ntropologia Del Trabajo, no VII Congreso A rgentino de Antropologia Social, Villa Giardino, Córdoba, Argentina, de 25 a 28 de maio de 2004.

** Professor do Departamento de Sociologia/CCHS, da Universidade de Caxias do Sul (UCS).
}

A flexibilização das relações de trabal ho e seus impactos no mercado de trabal ho têm sido objeto de análise de inúmeros trabalhos sociológicos. U ma recente incursão na sociologia do trabalho e na sociologia do futebol revelou-nos a necessidade de estudos que abordem o futebol como trabal ho, pois são raras as pesquisas preocupadas com 0 mundo do trabalho no esporte. ${ }^{1}$ O ptamos por investigar al gumas transformações em curso no mercado de trabalho do futebol brasileiro. Busca-se

\footnotetext{
1. A indústria do esporte é uma das que mais cresce no Brasil. Tem participação relevante no PIB. "Um estudo realizado pela Fundação Getúlio Vargas (FGV), encomendado pela Confederação Brasileiro de vôlei (CBV), revelou que a indústria do esporte é a que mais cresce no Brasil. Enquanto em 1997 as vendas de produtos e serviços esportivos cresceram $5,14 \%$, os demais setores industriais obtiveram, juntos, uma média de 3,9\%. A participação do setor esportivo no Produto Interno Bruto (PIB) brasileiro vem crescendo de forma gradual, segundo o estudo subiu de 1,5\% em 1995 para 1,65\% em 1997 e 1,7\% no ano seguinte" (In: http://www.futeboltotal.com. A cesso em: 5/3/1999).
} 
verificar os impactos que o fim do passe tem provocado no sistema de transferências de jogadores, nas relações contratuais, nos salários e na formação de jogadores.

Os procedimentos metodológicos utilizados foram pesquisa documental, entrevistas semiestruturadas, questionários, os quais foram anal isados por meio da utilização do programa informacional SPSS, e análise de conteúdo.

\section{A sociologia do trabalho e a flexibilização} das relações de trabalho no Brasil

\section{Conceito de flexibilidade}

0 termo flexibilidade tem sido empregado com diversos significados. Designa processos heterogêneos, na medida em que podem ser relacionados às necessidades geradas pelo tipo de processo de trabalho, de produto, de mercado, de estratégia competitiva, da organização e das relações de trabal ho em cada sistema produtivo (Salerno, 1995). Sayer e Walker (1994) apresentam uma classificação de flexibilidade: emprego flexível, processos de trabalho flexíveis, flexibilidade no volume de produção, flexibilidade do produto, flexibilidade da reestruturação e formas flexíveis de organização. ${ }^{2}$

A flexibilidade do trabalho abrange concretamente quatro dimensões: (1) emprego, (2) conteúdo do trabalho, (3) jornada de trabalho e (4) remuneração.

\section{A flexibilidade no emprego}

refere-se à quebra na rigidez das condições de contratação e demissão de trabalhadores ("flexibilidade externa") e de transferência e promoção dentro da empresa ("flexibilidade interna"). Os exemplos incluiriam a desregulação das demissões, 0 aumento da mobilidade lateral de trabal hadores (entre empregos, turnos etc.) e a maior liberdade de ação gerencial na determinação de promoções em geral, acompanhadas de supostos indicadores de performance. (M artin, 1997, p. 11)

A flexibilidade no conteúdo do trabal ho trata de uma maior amplitude e variação na natureza

2. Para definições dos tipos de flexibilidade, ver Sayer e Walker, La nueva economia social, p. 282. do trabalho. Por exemplo: ampliação ou eliminação de cargos polival entes, grupos autônomos que realizam determinadas tarefas no processo de produção.

A flexibilidade de remuneração toma a remuneração com base no incentivo, no mérito e nas competências. Os salários tornam-se parciais ou totalmente contingentes, conforme certos objetivos e indicadores de performance (M artin, 1997, p. 11-12).

Flexibilidade najornada de trabal ho "referese a uma crescente variação na duração e periodicidade da jornada 'regular' (isto é, excetuando horas extras) dos empregados" (M artin, 1997, p. 12). Por exemplo, as jornadas flexíveis, os turnos de revezamento etc.

A flexibilidade do trabalho, conforme as quatro dimensões acima tratadas, constitui característica básica de praticamente quase todos os model os de produção contemporâneos.

Deve-se evitar confusão entre flexibilidade do trabalho (flexibilidade no uso da força de trabalho pelos empregadores) e a noção de especialização flexível (designa um padrão de relações entre empresas e delas com o Estado, no qual as relações de trabalho são de natureza secundária). Não há um modelo único de flexibilidade do trabal ho. A flexibilidade pode ser mais opressiva, mais inclusiva, mais participativa. As práticas flexíveis podem incluir diversas formas de relações sociais (M artin, 1997, p. 13).

\section{A flexibilização do trabalho no Brasil}

As transformações na economia brasileira nas décadas de 1980 e 1990 impulsionaram a flexibilização na economia e no trabalho. 0 debate acerca da necessidade da mudança na legislação trabalhista iniciou-se na década de 1980, intensificando-se na década de 1990, momento marcado por medidas de abertura comercial e reinserção do país no contexto econômico gl obal izado. A s primeiras iniciativas de mudança na legislação trabal hista brasileira partiram dos governos Fernando Collor de M ello e Fernando Henrique Cardoso.

As medidas adotadas no B rasil podem ser classificadas, no que diz respeito à flexibilidade do trabal ho, como do tipo "neoliberal", conforme 
esquema explicativo de Dal-Ré. ${ }^{3} \mathrm{~A}$ descentralização das negociações col etivas contribuiu para fragilizar o poder sindical, reduzindo seus espaços e mecanismos de representação. A s mudanças implementadas pelo governo Fernando Henrique Cardoso na legislação sindical significaram transformações no papel designado ao Estado, de regulamentação das relações entre patrões e empregados. Houve "uma tentativa de flexibilização das relações de trabalho na supressão das políticas salariais e de reajustes do salário mínimo, expondo as categorias com pouca mobilização sindical a índices menores de reajustes salariais" (N ascimento e Segre, 2002, p. 6).

A sociologia do futebol e as novas relações de trabalho

0 fim do passe é resultado do conjunto de mudanças na legislação e na estrutura administrativa do futebol, que teve início com a criação do Clube dos Treze, em 1987, consolidando-se com a promulgação da Lei Pelé, e, mais especificamente, com o artigo que estabelece liberdade de trabal ho ao jogador de futebol. Três fatores desencadearam o fim do passe no futebol brasileiro, a saber: (1) o movimento do Clube dos Treze, (2) a Lei Zico, e (3) a Lei Pelé. A presentaremos detalhadamente cada um deles.

\section{0 movimento do Clube dos Treze ${ }^{4}$}

Movimento criado em julho de 1987, recebeu o nome oficial de U nião dos Grandes

\footnotetext{
3. Dal-Ré (1999) apresenta uma classificação com base em três modelos de flexibilização das relações de trabalho, tomando como caso concreto o processo de desregulamentação na Espanha: (1) tipo "neoliberal" - estabelece a desregulamentação a partir da supressão da legislação estatal que fixa condições de trabalho de caráter mínimo; (2) tipo "laissez-faire coletivo" - busca compensar as perdas dos direitos através do reforço dos instrumentos de representação coletiva do trabalho; (3) tipo "flexibilização de adaptação ou de ajuste à crise" - caracteriza-se pela introdução de correções que buscam diminuir a abrangência da legislação do trabalho, sem alterar seus fundamentos teóricos e suas estruturas normativas.

4. Entre os antecedentes da formação do Clube dos Treze, está a mudança nas regras do Campeonato Brasileiro de 1986, que teve por objetivo favorecer um grande clube do Rio de Janeiro (Pimenta, 2000, p. 80; Helal, 1997, p. 84).
}

Clubes Brasileiros. Formado pelos principais clubes de São Paulo, Rio de J aneiro, Rio G rande do Sul, M inas Gerais e Bahia, questionou e abalou a estrutura administrativa do futebol brasileiro. Os times participantes inicialmente eram São Paulo, Flamengo, Vasco, B otafogo, Corinthians, Palmeiras, Santos, Internacional, Grêmio, Cruzeiro, B ahia, Vitória eA tlético-M G.

0 Clube dos Treze reivindicou a modernização da estrutura administrativa do futebol nacional, tendo como model o as ligas européias de futebol. Fundar um liga nacional para gerir o futebol e organizar o campeonato nacional eram al guns dos seus propósitos.

A Copa União, campeonato nacional organizado em 1987 pelo Clube dos Treze, foi uma tentativa de racional izar e comercializar o campeonato brasileiro. Em outras palavras, os grandes clubes rebelaram-se contra a Confederação $B$ rasileira de $F$ utebol (CBF), que havia declarado ser incapaz de organizar o certame nacional naquele ano. 0 Clube dos Treze, apoiado pela TV Globo, Coca-Cola e Varig, realizou então a Copa União. Com exceção de Corinthians e Flamengo, todos os clubes participantes assinaram contratos de patrocínio com a CocaCola. Este pode ser considerado um momento decisivo na inserção definitiva do futebol nacional no futebol industrializado, dominado pelos empresários.

\section{A Lei Zico}

A Lei Zico insere-se em um contexto político de redefinição da intervenção estatal na esfera esportiva e de revisão do papel do Conselho Nacional de D esportos em relação à legislação esportiva.

No âmbito da economia, os anos 1990 assistiram a um conjunto de alterações: reestruturação produtiva; plano de combate à inflação; valorização e criação de uma nova moeda (o real, a partir de 1994); abertura da economia interna ao mercado internacional; privatização de empresas estatais, e flexibilização das relações de trabal ho. 0 país adota 0 discurso da globalização e do liberalismo, substituindo o modelo nacional-desenvolvimentista pelo modelo-discurso da eficiência do mercado. 0 primeiro parecia ultrapassado, 
enquanto o segundo representaria a modernidade.

No âmbito esportivo, as mudanças giravam em torno da melhoria de serviços prestados ao consumidor (torcedor) e do incentivo da participação da iniciativa privada no esporte, retirando parte do patrocínio público. Com isso, abria-se oportunidade para o avanço do marketing esportivo, uma das facetas do futebol-empresa em gestação. Tais mudanças pretendem libertar o futebol da tutela estatal. (Proni, 2000, p. 164)

0 "Projeto Zico", encaminhado ao Congresso Nacional em 1991, apresentava como conteúdo, segundo Proni (2000, p. 165):

i) regulamentar a presença de empresas e as formas de comercialização no futebol profissional, ii) rever a participação nos recursos da L oteria Esportiva, iii) extinguir a 'lei do passe' e estabelecer uma nova norma para o contrato de trabal ho do atleta profissional, iv) redefinir os mecanismos de supervisão e assegurar a autonomia estatuária dos clubes, assim como v) buscar mecanismos mais democráticos e transparentes de representação e de administração das federações e da CBF.

Pretendia-se modernizar o futebol brasileiro, bem como proporcionar melhores condições financeiras aos clubes nacionais, transformandoos em empresas comerciais de natureza desportiva. Com isso, era inevitável e necessária a profissionalização administrativa.

D epois de muitas discussões e reações dos dirigentes de clubes e federações, especial mente no que se referia ao fim do passe, o projeto foi aprovado com algumas modificações, entre elas a retirada do ponto que pregava o fim da lei do passe, além da obrigação de transformação dos clubes em empresas.

A Lei Zico (Lei n. 8.672/93) tinha por objetivo modificar a organização do futebol nacional, promovendo: (1) o fim do passe, proporcionando autonomia aos jogadores em forma de liberdade de contrato; (2) a ruptura com o modelo intervencionista do Estado nos clubes e federações; (3) o surgimento do futebolempresa; (4) al terações no sistema el eitoral da CBF (Pimenta, 2000, p. 81).
A modernização embutida na L ei Zico não se completou, ou melhor, realizou-se levando em conta a ética dual na qual o moderno e tradicional se mesclam. ${ }^{5}$ Por exemplo, jogadores profissionais e dirigentes amadores. Podem-se apontar outras falhas no projeto modernizante empreendido a partir da L ei Zico, como revela Helal:

A adoção do 'futebol-empresa', permitida após a L ei Zico [...] sem a transformação da estrutura de poder, não representa uma mudança radical na organização do futebol no país, pois a política de troca de favores ainda prevaleceria na organização dos campeonatos. Com jogos deficitários, o campeonato daria prejuízo aos clubes, limitando o potencial de marketing e da comercialização do futebol, e é exatamente isto o que vem ocorrendo mesmo após a L ei Zico. O u seja, a modernização administrativa, significando comercialização do espetáculo, teria que vir acompanhada de uma modernização política, entendida aqui como autonomia e independência dos clubes para organizar os campeonatos. (Helal, 1997, p. 111)

\section{A Lei Pelé}

Em setembro de 1997, Edson A rantes do Nascimento, o Pelé, ministro extraordinário dos Esportes, encaminhou projeto de lei que, inspirado na legislação espanhola, pretendia restaurar o controle do Estado sobre as entidades esportivas. Determinava a fiscalização do esporte e a autonomia dos clubes, no que se refere a sua organização. Segundo Proni (2000, p. 198),

[...] ao propor a revogação da L ei 6.354/76, o projeto também pretendia retirar as proteções que a legislação garantia aos clubes (lei do passe) e aos atletas ( $15 \%$ na transferência e limite de três anos na duração do contrato), deixando que o esporte passasse a ser regulado pelas leis do mercado.

\footnotetext{
${ }^{5}$ A sociedade brasileira conserva esse dilema: tradicional versus moderno em outras dimensões, tais como política, cultura e economia. Tradicional utilizado aqui no sentido do arcaico, a permanência dos dirigentes antigos que se tornaram verdadeiros donos dos clubes e federações. M oderno significa as inovações na legislação e na administração.
} 
0 projeto foi enviado ao Congresso Nacional sem qualquer consulta às entidades esportivas, o que levou dirigentes de clubes, da CBF e das federações estaduais a classificarem-no de "idiota", estatizante, autoritário. Os principais clubes brasileiros manifestaram-se contrários ao fim do passe estabelecido pela Lei Pelé, alegando que este era uma forma de repor os investimentos no processo de formação do atleta.

A modernização do futebol, a partir da década de 1990, pode ser entendida como resultado de mudanças na economia mundial e do processo de transformação do esporte em produto da indústria de entretenimento, em processo de globalização. Nesse sentido,

[...] a modernização do futebol brasileiro tornava-se um imperativo da concorrência capitalista; tornava-se urgente reestruturar as formas de produção do espetáculo e de gestão dos clubes para garantir uma alta competitividade internacional e alavancar os negócios nesse campo de valorização em franca expansão. (Proni, 2000, p. 193)

H avia uma consonância entre a adoção de um modelo de modernização na sociedade, via processo de globalização da economia, e as mudanças estruturais no futebol, também inspiradas na gestão do espetáculo futebolístico europeu. 0 padrão de gestão empresarial passou a ser considerado a solução para o futebol brasileiro. É nesse sentido que o discurso defensor da profissional ização dos dirigentes ganha adeptos, particularmente na imprensa. E stabeleceu-se uma estreita relação entre profissionalização da administração, transformação dos clubes em empresas, racionalização do calendário futebolístico e criação da liga nacional. Trata-se aqui de aspectos importantes da tão desejada moralização do futebol, conferindo transparência nas negociações entre clubes e nas relações entre jogadores e clubes. A crença era de que a modernização seria a solução para erradicar os males do futebol nacional.

A Lei Pelé (Lei n. 9.615/03/1998) determina que os atletas profissionais de futebol, de qualquer idade, têm liberdade para assinar contratos com os clubes que oferecerem mel hores propostas. 0 vínculo que garantia ao clube a força de trabalho do atleta, permitindo até mesmo vendê-la, foi abolido. A o término decada contrato, 0 atleta profissional tem liberdade de procurar outra entidade desportiva ou permanecer na que estava, em caso de acerto de ambas as partes.

Com essa lei, o jogador de futebol deixa sua condição de mera mercadoria, não sendo mais patrimônio do clube para se tornar um empregado, um trabal hador da bola.

0 fim do passe significa uma redefinição nas relações entre jogadores e clubes no futebol brasileiro. Representa, por um lado, liberdade de trabalho e flexibilização do sistema de transferências e, por outro lado, o fim de uma garantia de emprego, provocando desemprego e encurtamento da carreira do jogador de futebol. 0 passe, mesmo sendo um mecanismo paternalista e servil, era uma das facetas da estabilidade na carreira do jogador de futebol. 0 fim do passe poderá levar ao fim das categorias de base nos clubes e, conseqüentemente, à privatização do futebol, via proliferação de escolinhas particulares. Nestas não basta talento, é necessário dinheiro para pagar mensalidades (Pimenta, 2000). A elitização do futebol brasileiro poderá ser a conseqüência da nova configuração das políticas de formação de jogadores, a partir do fim do passe. É possível que ocorra a transição do futebol como profissão e mecanismo de ascensão social para uma profissão de classe média.

0 fim do passe também representa uma faceta do sistema de acumulação flexível no futebol, facilitando os contratos temporários e um rejuvenescimento da força de trabalho no futebol brasileiro. 0 que, em outras palavras, pode ser 0 encurtamento da vida útil do atl eta.

0 discurso defensor da lei do passe mostra uma sintonia com o neoliberal ismo, no qual é o mercado que redefine as relações. Para Hélio Vianna, vice-presidente do Conselho Deliberativo do Idesp, o fim do passe acaba com 0 paternal ismo no futebol e moderniza as relações.

Com a Lei, não vai ter mais clube vendendo jogador. Vai ser sempre como no caso do Ronal dinho. 0 jogador recebe proposta mel hor, paga a multa e vai embora [...]. N ão pode haver paternalismo. Esse projeto não é para proteger jogador. É para colocar o futebol na moderni- 
dade [...]. Com os clubes-empresa, em um ano somem os Euricos da vida. A relação vai ser profissional. É claro que um ou outro [jogador] vai assinar em branco. $\mathrm{M}$ as depois aprende $\mathrm{e}$ não faz mais. [...] 0 mercado é sábio. N ele, os jogadores são trabalhadores normais. Sem as leis especiais, a categoria vai crescer e vai se conscientizar. Como em toda parte, quem negociar melhor vai sair ganhando. (Proni, 2000, p. 200-201)

Os times têm como gastos principais os investimentos na aquisição de atletas (compra de passes) e outras despesas (bichos, prêmio, salários).

0 maior problema dos clubes brasileiros é que o crescimento das receitas não é suficiente para cobrir os gastos com salários dos jogadores, diferentemente do que ocorre na Europa.

A formação de atl etas poderá deixar de ser uma atividade compensadora. Os empresários terão maior poder de ação, pois serão eles que farão, diretamente com os clubes, as transações de jogadores. Faz sentido questionar os debates e interesses na questão do passe: por que tanta polêmica a respeito do fim do passe? 0 que os jogadores acham disso? Q ual a reação dos atletas e dirigentes? Para essas perguntas não temos respostas ainda, mas pretendemos respondê-las em nossa tese de doutorado. ${ }^{6}$

Faz-se necessário questionar como o fim do passe causa impacto na mobilidade de jogadores entre regiões do país, bem como na migração de jogadores para outros países. Segundo Giulianotti (2002, p. 159), houve crescimento substancial na mobilidade de atletas no futebol europeu pós-"caso B osmann". M uitos atletas espanhóis, italianos, franceses e alemães deixaram sua terra natal para trabalhar em outros países.

Os grandes clubes tornaram-se mais poderosos e ricos no futebol europeu, dominando os campeonatos, e contratando os melhores jogadores, sejam eles nacionais ou estrangeiros. N osso trabal ho preocupa-se em verificar se isso ocorreu também no futebol brasileiro. M esmo sendo demasiadamente prematuro fazer

\footnotetext{
${ }^{6}$ Futebol e civilização: o fim do passe e a modernização conservadora no futebol brasileiro (2001-2004) é o título de nossa tese de doutorado em sociologia (UFRGS), que está em fase de elaboração.
}

prognósticos, o economista M arcelo Proni (2000) aponta que éinevitável a concentração de poder econômico e político entre os grandes clubes do nosso futebol.

No caso do futebol brasileiro, entre 1997 e 2000, houve elevação nos salários de alguns atletas, especialmente da elite. Porém, nos últimos dois anos, percebe-se um movimento de redução da média salarial - os grandes jogadores do país tiveram seus salários reduzidos, inclusive Romário. 0 salário de Romário no Vasco da Gama, em 2000, era R \$ 400 mil. Em 2001, a direção do Vasco da Gama reduziu esse montante para $\mathrm{R} \$ 250$ mil e, no segundo semestre de 2002, declarou-se sem condições financei ras para manter 0 atacante. Em agosto de 2002, Romário passou a receber apenas $R \$ 70 \mathrm{mil}$ para atuar pelo Fluminense. Outros jogadores tiveram salários reduzidos, como Zinho, M arques, Danrlei, Roger. M uitos clubes brasileiros diminuíram despesas, cortando salários. 0 Flamengo rebaixou sua folha mensal de $R \$ 3$ milhões para $\mathrm{R} \$ 557$ mil. 0 atleta M arques, atacante do Atlético-MG, aceitou, para permanecer empregado no clube mineiro, redução no salário de $\mathrm{R} \$ 160$ mil para $\mathrm{R} \$ 50$ mil (Correa, 2002, p. 47).

Os grandes clubes ${ }^{7}$ do futebol brasileiro estabeleceram um teto salarial máximo de $\mathrm{R} \$$ 50 mil. A redução salarial atinge os técnicos. As cifras que alcançavam até $R \$ 150 \mathrm{mil}$ no ano passado agora baixaram para, no máximo, $\mathrm{R} \$ 60 \mathrm{mil}$.

Inquieta-nos o fato de que, no futebol europeu, houve crescimento do nível salarial após o fim do passe (Giulianotti, 2002), enquanto no Brasil a tendência é contrária. Que relação existe? Será que é a crise econômica do país ou as mudanças na legislação futebolísticas que redefinem as políticas salariais dos clubes? São questões para as quais não temos respostas ainda.

A sociologia do futebol brasileiro e o fim do passe

$\mathrm{Na}$ análise do caso brasileiro, tomaremos, como referencial, alguns estudos sobre 0

\footnotetext{
${ }_{7}^{7}$ Entre estes clubes, estão SC Internacional-RS, Santos FC, A tlético-M G, CR Flamengo e Vasco da Gama.
} 
processo de modernização do futebol brasileiro (Helal, 1997; Proni, 2000) e acerca da nova configuração do mercado futebolístico nacional, após a famosa Lei Pelé (A raújo, 1980; Florenzano, 1998; R odrigues, 2004 e 2003).

Em Os gênios da pelota, A raújo (1980) elabora uma etnografia sobre o futebol como profissão. Trata-se de um trabal ho que se tornou referencial para futuras investigações sobre 0 futebol como campo de trabal ho, por se tratar de uma pesquisa pioneira a respeito dessa modalidade de esporte como profissão nos anos 1980. O estudo do futebol como profissão, especialmente no que se refere à motivação profissional, pode adotar a oposição cálculoprazer. Esta é uma perspectiva seguida por A raújo, que busca entender as razões que levaram os jogadores pesquisados a escol her o futebol como profissão, e a concepção que eles têm dessa carreira profissional (A raújo, 1980, p. 5).

Sobre o passe, A raújo afirma o seguinte:

O passe implica, fundamentalmente, uma 'carta' que assegura ao clube direitos absolutos sobre a transferência do jogador. Este documento, 0 'Certificado de Transferência', vincula inteiramente o jogador ao clube, que tem a propriedade do seu passe. Conseqüentemente, para mudar de clube, de emprego, o jogador terá que ser vendido ou trocado, em negociações nas quais, embora consultado, nunca possui a palavra final. (A raújo, 1980, p. 75)

0 passe era um mecanismo legal, criado pela L ei n.6.354, de 2/9/76, regulamentando a profissão de jogador de futebol. L ogo, o jogador éo trabalhador legalmente proibido de procurar emprego, de escolher. Não é dono de seus interesses e destino profissionais. 0 passe éuma instituição paternalista. A trapal ha o projeto de acumulação do jogador, mas Ihe dá o mínimo de segurança. A raújo conclui que os atletas consideram o passe uma segurança de emprego, porém também significa privação da autonomia de trabalho. Com o fim do passe, os jogadores ganhariam autonomia, mas perderiam em segurança.

Florenzano (1998) analisa dois casos especiais: 0 de A fonsinho e o de Edmundo. Em 1971, A fonsinho ganhou passe livre. N esse ano, outros jogadores também reivindicaram passe livre, como Paulo César e Raul, sendo ambos ameaçados. Com o passe em vigor, 0 atleta é tratado como um objeto à venda.

No caso de A fonsinho, é ilustrativo o fato de que o passe prendia- 0 ao B otafogo. 0 clube proibiu 0 atleta de treinar e jogar enquanto estivesse barbado e de cabelos grandes. A pós o término do contrato, depois de ficar seis meses parado, proibido de exercer a profissão pelos dirigentes do Botafogo, $A$ fonsinho recorreu à justiça desportiva, solicitando o direito de trabal har em outro clube. Porém, a lei do passe estava em vigor. A conseqüência é que esse jogador, após cinco anos de trabal ho no clube carioca, viu-se aprisionado, pois foi, em represália a sua conduta indisciplinada, proibido de jogar futebol, ficando sem salário, sem trabalho e impossibilitado de procurar outro clube. 0 atleta teve seu contrato suspenso e foi afastado da equipe.

0 passe retirava do jogador a propriedade de sua força de trabalho, tornando-o uma mercadoria-trabalho.

Com relação ao caso Edmundo, deve-se ressaltar que 0 Corinthians queria contratar 0 atl eta por um preço baixo, porém Edmundo não queria voltar ao futebol paulista. Aí entram em cena debates sobre o passe. Conforme palavras de Edmundo: "O passe é do clube, mas a vida é minha e ainda vou decidir meu futuro" (J ornal da Tarde, 28/12/1995). Enquanto isso, 0 Flamengo e 0 Corinthians negociavam o passe do atleta. Edmundo considerava aquilo uma derrota pessoal, pois não desejava mais retornar ao futebol de São Paulo, por ter prometido isso ao deixar o Palmeiras (Florenzano, 1998, p. 225).

M esmo sem querer, 0 atacante vol tou para São Paulo, sendo obrigado pelo passe, meio de dominação no futebol. Paternal ista e instrumento de uma relação de trabal ho que vê o atleta como criança, o passe tira a autonomia de trabal ho do atleta, tendo a função política de mantê-lo sob minoridade.

Com a lei do passe, o jogador era objeto. A ssim, com o fim do passe, muda-se a condição do atleta. Em editorial intitulado "O fim da escravidão", o jornal Folha de S. Paulo manifestou-se da seguinte forma a respeito da questão: 
A nova regulamentação que trata da questão dos passes de jogadores de futebol [...] caminha no rumo correto de pôr um fim ao regime de escravidão a que estão submetidos os atl etas desta modal idade esportiva no B rasil [...] Se um executivo, por exemplo, pode trocar de empresa à hora que bem entender, ressalvadas cláusulas especiais acertadas previamente por ambas as partes, por que um atl eta não pode fazer o mesmo? [...] 0 fato concreto é que a Lei Á urea data de 1888, só agora, em 1997, os jogadores de futebol encontram sua alforria. (F olha de S. Paulo, 12/9/1996)

Somente agora é que o profissional do futebol começa a ser um cidadão livre para trabalhar, dono de seu destino. 0 passe era inadmissível. A ssim, um cronista esportivo reconhecido nacionalmente manifestava-se: "0 regime do passe, tal como existe no Brasil, é odioso. 0 atleta é vendido e comprado, entre clubes, como se não fosse gente. 0 jogador, quase sempre, não é ouvido, nem cheirado. Vai para onde não quer ir, negociado como saco de batatas" (Nogueira, Jornal do Brasil, 15/9/ 1996).

O fim do passe no Sport Club Internacional: a concepção dos jogadores

M uitas controvérsias e discussões vieram à tona após a promulgação da referida lei, porém não se tem um consenso sobre suas reais conseqüências no futebol brasileiro. Não há estudos que apontem claramente os impactos que terá no mercado futebolístico brasileiro. Sabe-se que deve mudar a política de formação de jogadores por parte dos clubes.

Vejamos o que pensam os jogadores entrevistados sobre o fim do passe. 0 gráfico 1 apresenta duas visões antagônicas. Para 70\% dos atletas, o fim do passe é positivo. Estes acreditam em futuras melhoras no futebol, diferentemente dos $30 \%$ de pessimistas que avaliam negativamente o mesmo fenômeno.

Tentando captar melhor a avaliação dos atletas sobre os impactos do fim do passe, a pesquisa sugeriu al gumas alternativas. Vejamos, em termos percentuais, como essas alternativas foram recebidas pelos atletas.

0 gráfico 2 revela que o fim do passe representa liberdade de trabal ho para $46 \%$ dos

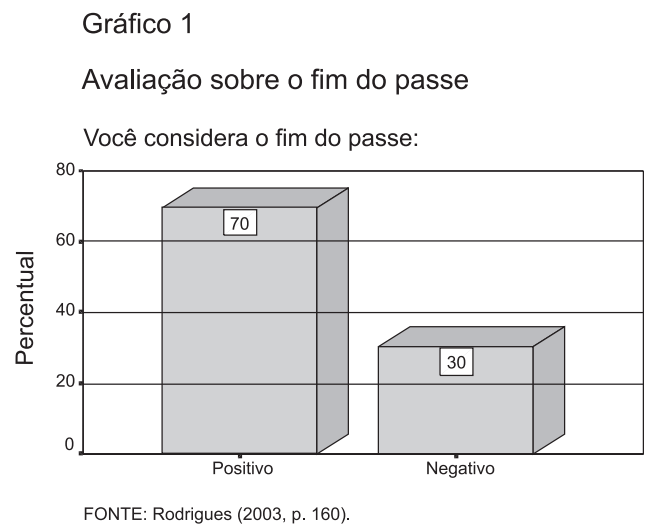

Gráfico 2

Visão geral sobre o fim do passe

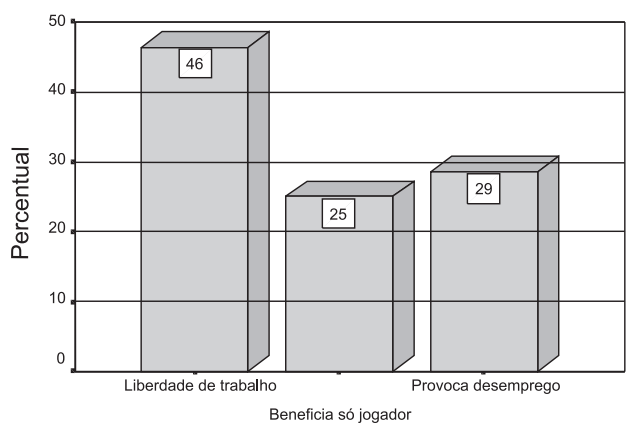

FONTE: Rodrigues (2003, p. 160)

jogadores. Trata-se de um dado significativo, manifestando otimismo quanto ao processo de modernização das leis trabal histas no universo do futebol. Entre esses otimistas, a maior parcela é formada pelos atletas profissionais, os que mais sentem diretamente as conseqüências da nova legislação.

Por outro lado, percebe-se que $29 \%$ dos atletas são pessimistas em relação ao futuro do mercado futebolístico nacional, com a entrada em vigor do fim do passe. Para eles, o fim do passe significa desemprego. Os jogadores perderão 0 vínculo com o clube e serão mais facilmente esquecidos pelo mercado, o que poderá abreviar a duração das suas carreiras. 0 que é lastimável, porém possível de acontecer realmente.

Há uma outra parcela significativa de jogadores queavaliam o fim do passe da seguinte forma: beneficiará apenas jogadores famosos $(25 \%)$. 
A Iguns cruzamentos foram realizados tomando como categoria-chave a concepção sobre o fim do passe. A tabela 1 apresenta, em termos de tendências, eventuais relações entre escolinha de futebol, renda familiar e a opinião dos atletas sobre o fim do passe.

Os jogadores provenientes de famílias com renda entre um e três salários mínimos, na sua maioria, passaram por escolinhas de futebol $(66,7 \%)$. Destes, $50 \%$ consideram que o fim do passe provoca desemprego no futebol, enquanto, para $25 \%$ dos atletas, o fim do passe significa liberdade de trabal ho. Outros $25 \%$ consideram que apenas jogadores famosos serão beneficiados. Portanto, dentro do universo de atletas com menor renda familiar, a visão predominante sobre o fim do passe é desemprego $(44,4 \%)$ e liberdade de trabalho $(38,9 \%)$.

Podemos observar que $56,3 \%$ dos atletas que passaram por escolinha e que têm renda familiar de quatro a seis salários mínimos consideram que o fim do passe beneficiará apenas os jogadores famosos. Vinte e cinco por cento dos atletas que passaram por escolinha, e com esse mesmo nível de renda familiar, avaliam que o fim do passe proporcionará liberdade de trabalho no futebol.

Para $61,1 \%$ dos atletas que passaram por escolinha, com renda familiar acima de sete salários mínimos, o fim do passe dará liberdade de trabalho aos jogadores de futebol. M esmo não tendo passado por escolinha, todos os atletas

Tabela 1 - VISÃ O SOBRE O FIM DO PASSE (A bs. e\%)

\begin{tabular}{|c|c|c|c|c|c|}
\hline \multirow{2}{*}{$\begin{array}{l}\text { Passou por } \\
\text { escolinha de } \\
\text { futebol }\end{array}$} & & \multicolumn{3}{|c|}{ Visão sobre o "Fim do Passe" } & \multirow[b]{2}{*}{ Total } \\
\hline & & $\begin{array}{l}\text { Liberdade de } \\
\text { trabalho }\end{array}$ & $\begin{array}{c}\text { Beneficia só } \\
\text { jogadores } \\
\text { famosos }\end{array}$ & $\begin{array}{c}\text { Provoca } \\
\text { desemprego }\end{array}$ & \\
\hline \multirow{5}{*}{ Sim } & Até $3 \mathrm{SM}$ & $\begin{array}{r}3 \\
25,0 \\
16,7\end{array}$ & $\begin{array}{r}3 \\
25,0 \\
21,4\end{array}$ & $\begin{array}{r}6 \\
50,0 \\
42,9\end{array}$ & $\begin{array}{r}12 \\
100,0 \\
26,1\end{array}$ \\
\hline & 4 a $6 \mathrm{SM}$ & $\begin{array}{r}4 \\
25,0 \\
22,2\end{array}$ & $\begin{array}{r}9 \\
56,3 \\
64,3\end{array}$ & $\begin{array}{r}3 \\
18,8 \\
21,4 \\
\end{array}$ & $\begin{array}{r}16 \\
100,0 \\
34,8\end{array}$ \\
\hline & 7 a $10 \mathrm{SM}$ & $\begin{array}{r}6 \\
60,0 \\
33,3\end{array}$ & $\begin{array}{r}1 \\
10,0 \\
7,1\end{array}$ & $\begin{array}{r}3 \\
30,0 \\
21,4\end{array}$ & $\begin{array}{r}10 \\
100,0 \\
21,7\end{array}$ \\
\hline & Mais de $10 \mathrm{SM}$ & $\begin{array}{r}5 \\
62,5 \\
27,8 \\
\end{array}$ & $\begin{array}{r}1 \\
12,5 \\
7,1 \\
\end{array}$ & $\begin{array}{r}2 \\
25,0 \\
14,3 \\
\end{array}$ & $\begin{array}{r}8 \\
100,0 \\
17,4 \\
\end{array}$ \\
\hline & Total & $\begin{array}{r}18 \\
39,1 \\
100,0\end{array}$ & $\begin{array}{r}14 \\
30,4 \\
100,0\end{array}$ & $\begin{array}{r}14 \\
30,4 \\
100,0\end{array}$ & $\begin{array}{r}46 \\
100,0 \\
100,0\end{array}$ \\
\hline \multirow{4}{*}{ Não } & Até $3 \mathrm{SM}$ & $\begin{array}{r}4 \\
66,7 \\
50,0 \\
\end{array}$ & & $\begin{array}{r}2 \\
33,3 \\
100,0 \\
\end{array}$ & $\begin{array}{r}6 \\
100,0 \\
60,0 \\
\end{array}$ \\
\hline & 4 a $6 \mathrm{SM}$ & $\begin{array}{r}1 \\
100,0 \\
12,5 \\
\end{array}$ & & & $\begin{array}{r}1 \\
100,0 \\
10,0 \\
\end{array}$ \\
\hline & 7 a $10 \mathrm{SM}$ & $\begin{array}{r}3 \\
100,0 \\
37,5\end{array}$ & & & $\begin{array}{r}3 \\
100,0 \\
30,0\end{array}$ \\
\hline & Total & $\begin{array}{r}8 \\
80,0 \\
100,0\end{array}$ & & $\begin{array}{r}2 \\
20,0 \\
100,0\end{array}$ & $\begin{array}{r}10 \\
100,0 \\
100,0\end{array}$ \\
\hline
\end{tabular}

SM = Salário Mínimo

Fonte: Rodrigues (2003) 
com essa mesma renda familiar têm também tal concepção.

A tabela 2 é bem mais detalhista e informativa do que a anterior. Indica o que as três categorias avaliam e pensam sobre as conseqüências do fim do passe. A opinião predominante é de que os atletas ganharão mais liberdade de trabalho (46,4\%). O utras opiniões são importantes, como a possibilidade de beneficiar apenas os jogadores já consagrados no futebol $(25 \%)$ e de se tratar do fim de uma garantia de emprego (25\%), que, na prática, acarretaria desemprego. Para $40 \%$ dos atletas juvenis, o fim do passe beneficiará apenas os jogadores famosos. Isso explica por que eles consideram o fim do passe negativo. Como se sabe, nessa categoria, o mercado futebolístico não oferece grandes possibilidades - praticamente não há remuneração, nem competições muito valorizadas. Tendo isto em mente, podese afirmar que são raros os atletas juvenis já famosos. Nessa mesma categoria, uma significativa parcela, al go em torno de $30 \%$ considera que o fim do passe dará liberdade de trabalho aos jogadores de futebol.

Os juniores avaliam que o fim do passe implica liberdade de trabal ho (45\%) e desemprego (35\%). Trata-se de uma visão positiva, porém bastante cautel osa, reforçando a resposta anterior, em que $75 \%$ deles responderam que 0 fim do "passe" é positivo. A avaliação mais otimista é aquela defendida pelos atletas profissionais. Segundo $68,8 \%$ deles, a liberdade de trabal ho será o principal resultado do fim do passe. Isso é interessante e reforça 0 argumento anterior de que mais de $90 \%$ dos profissionais avaliam positivamente 0 fim do passe.

Vejamos o depoimento de um atleta sobre o fim do passe, no qual se percebe muito pessimismo e cautela:

Depende, acho que a lei do passe é muito boa para quem já tem seu nome feito no mercado do futebol, porque ele vai ficar livre, vai para 0 time que quiser. $M$ as para jogadores do interior que não têm seu nome feito, que ainda não jogaram em equipes boas como a equipe do Inter, vai ser muito ruim, porque eles não têm seu nome feito, então vão ter que correr atrás de clubes. Eu acho que para esses jogadores mais humildes, mais simples, vai ser muito ruim. (A tleta 1 )

Por outro lado, alguns atletas apresentam visão otimista em relação aos impactos provocados pelo fim do passe. Vejamos um deles:

Tabela 2 - CONCEPÇÃ O SOBRE O FIM DO PASSE (A bs. e\%)

\begin{tabular}{|c|c|c|c|c|c|}
\hline \multirow[b]{2}{*}{ Categoria } & \multicolumn{4}{|c|}{ Como avalia o fim do passe } & \multirow[b]{2}{*}{ Total } \\
\hline & Liberdade & $\begin{array}{l}\text { Beneficiará } \\
\text { somente } \\
\text { jogadores } \\
\text { famosos }\end{array}$ & $\begin{array}{l}\text { Provocará } \\
\text { desemprego }\end{array}$ & $\begin{array}{l}\text { É o fim de uma } \\
\text { garantia de } \\
\text { emprego, porém } \\
\text { há ganhos de } \\
\text { autonomia }\end{array}$ & \\
\hline Juvenil & $\begin{array}{r}6 \\
30,0 \\
23,1\end{array}$ & $\begin{array}{r}8 \\
40,0 \\
57,1\end{array}$ & $\begin{array}{r}1 \\
5,0 \\
50,0\end{array}$ & $\begin{array}{r}5 \\
25,0 \\
35,7\end{array}$ & $\begin{array}{r}20 \\
100,0 \\
35,7\end{array}$ \\
\hline Júnior & $\begin{array}{r}9 \\
45,0 \\
34,6\end{array}$ & $\begin{array}{r}4 \\
20,0 \\
28,6\end{array}$ & & $\begin{array}{r}7 \\
35,0 \\
50,0\end{array}$ & $\begin{array}{r}20 \\
100,0 \\
35,7\end{array}$ \\
\hline Profissional & $\begin{array}{r}11 \\
68,8 \\
42,3\end{array}$ & $\begin{array}{r}2 \\
12,5 \\
14,3\end{array}$ & $\begin{array}{r}1 \\
6,3 \\
50,0\end{array}$ & $\begin{array}{r}2 \\
12,5 \\
14,3\end{array}$ & $\begin{array}{r}16 \\
100,0 \\
28,6\end{array}$ \\
\hline Total & $\begin{array}{r}26 \\
46,4 \\
100,0\end{array}$ & $\begin{array}{r}14 \\
25,0 \\
100,0\end{array}$ & $\begin{array}{r}2 \\
3,6 \\
100,0\end{array}$ & $\begin{array}{r}14 \\
25,0 \\
100,0\end{array}$ & $\begin{array}{r}56 \\
100,0 \\
100,0\end{array}$ \\
\hline
\end{tabular}

Fonte: Rodrigues (2003) 
Será mel hor não só para o jogador, mas para o clube também, porque 0 jogador fica na obrigação de estar sempre bem, sempre trabal hando para que consiga sempre contrato, sempre clubes interessados e com certeza vai ser bom para o jogador e para o clube. Essa lei faz com que o jogador trabal he e fique sempre em boas condições para que sempre tenha portas abertas e clubes interessados, porque pode ser que ele fique desempregado e esquecido do mercado. (A tleta 2)

A presentaremos outras opiniões sobre o fim do passe para que o leitor possa perceber como se trata de uma questão ainda muito controversa. Veja al gumas:

0 fim do passe é negativo porque muitos jogadores encerrarão a carreira. (A tleta 11)

Positivo, el ese torna dono del e mesmo. (A tleta, 23)

Negativo, al guns jogadores ficam sem clube de futebol onde trabalhar. (A tleta 26)

N egativo, alguns ficam desempregados. (A tleta 28)

Negativo, porque prejudica a maioria dos atletas e favorece apenas os grandes jogadores. (A tleta 15)

Positivo, é onde o jogador vê qual lugar é melhor para ele trabal har. (A tleta 1 )

A s opiniões dividem-se entre liberdade de trabal ho e desemprego. No entanto, é necessário ressaltar que os impactos provocados pela nova legislação trabal hista no mercado de trabal ho e na política de formação de jogadores nos clubes ainda são desconhecidos. A lei que garante 0 fim do passe tem pouco mais de um ano de vigência e, além do mais, vem sendo constantemente desrespeitada por parte de empresários e dirigentes de clubes. Portanto, é preciso aguardar mais para poder fazer uma análise mais consistente.

\section{Consider ações finais}

Neste trabal ho, procuramos analisar, a partir de uma investigação empírica, a flexibilização das relações de trabalho no futebol brasileiro, expressa no fim do passe. A literatura produzida na sociologia do trabalho e na sociologia do futebol foi a principal fonte teórica.
As transformações no mundo do trabalho no Brasil foram intensificadas na década de 1990, especial mente com a abertura comercial, as privatizações e as inovações tecnológicas e organizacionais implementadas nos governos de Fernando Collor de M ello e Fernando Henrique $C$ ardoso. U m fato interessante é que é também nesse momento que a flexibilização nas relações de trabal ho no mundo do futebol começou a ser discutida e implementada, gradativamente, no $B$ rasil. Entretanto, ainda inquieta-nos o fato de que são poucos os sociólogos do trabal ho e do futebol interessados em investigar a nova regulamentação do mercado de trabalho no futebol brasileiro. Consideramos que há muito 0 que esclarecer sobre as relações entre clubes e jogadores, empresários e clubes, empresários e jogadores. Nossa modesta pretensão, neste exercício empírico, era iniciar esse debate e apontar questões.

Sintetizando, a visão dos jogadores sobre os impactos do fim do passe é ambígua.

Vejamos agora os dados relativos ao fim do passe. Para $70 \%$ dos atletas do SC Internacional, o fim do passe é positivo. Confiam em futuras melhoras no universo do futebol, diferentemente dos $30 \%$ de pessimistas que avaliam negativamente esse fenômeno.

0 fim do passe significa liberdade de trabal ho para $46 \%$ dos atletas pesquisados. Trata-se de um dado ilustrativo, que manifesta otimismo quanto ao processo de modernização e flexibilização das leis trabal histas, no mercado de trabalho do futebol. Entre esses otimistas, a maior parcela é constituída pelos atletas profissionais. São os que mais sentem diretamente as conseqüências da nova legislação.

Percebe-se que $29 \%$ dos atletas são pessimistas em relação ao futuro do mercado futebolístico nacional, com a entrada em vigor da lei que estabelece o fim do passe. Para eles, o fim do passe representa desemprego. Os jogadores perdem 0 vínculo com o clube e correm o risco de ser facilmente esquecidos pelo mercado, sem espaço para treinar nem possibilidades de ser contratados, o que pode abreviar a duração das suas carreiras.

Há uma parcela significativa de jogadores (25\%) que avalia o fim do passe como al go que 
beneficiará somente os jogadores famosos, aqueles já consagrados no mercado de trabal ho.

N ossa pesquisa procurou demonstrar como as três categorias de jogadores do SC Internacional avaliam as conseqüências do fim do passe. A opinião predominante é de que os atletas ganharão mais liberdade de trabalho. Outras opiniões são importantes também, como a possibilidade de beneficiar apenas os jogadores já consagrados no futebol e de se tratar do fim de uma garantia de emprego, acarretando, na prática, desemprego. Para $40 \%$ dos atletas juvenis, o fim do passe beneficiará apenas os jogadores famosos. Isso explica por que eles consideram o fim do passe negativo. Nessa categoria, o mercado futebolístico não oferece grandes possibilidades, praticamente não há remuneração, nem competições muito valorizadas. São raros os atl etas juvenis já famosos. $\mathrm{N}$ essa mesma categoria, uma significativa parcela considera que o fim do passe dará liberdade de trabalho aos jogadores de futebol.

Os juniores avaliam que o fim do passe implica liberdade de trabalho e desemprego. Trata-se de uma visão positiva, porém bastante cautel osa, reforçando a resposta anterior, na qual $75 \%$ deles disseram que o fim do passe é positivo. A avaliação mais otimista sobre essa mesma questão é a defendida pelos atletas profissionais. Segundo 68,8\% deles, a liberdade de trabalho será o principal resultado da lei do passe. Isso é interessante e reforça 0 argumento anterior de que mais de $90 \%$ dos profissionais avaliam positivamente 0 fim do passe.

\footnotetext{
Abstract: The rehearsal analyzes the recent transformations in the world of the work of the Brazilian soccer starting from a dialogue between the sociology of the work and the sociology of the soccer. It is an investigation on the process of flexibility of the work relationships in the soccer, analyzing some of their impacts in the soccer gaucho in the period from 2001 to 2002. The flexibility of the work soccer has beginning with the Law n. 9.615/03/ 1998 that it establishes the end of the pass. W e verified that most of the players considers the modemization of the labor laws and the flexibility of the work relationships in the soccer as positive. The results appear that the main conceptions on the end of the healthy pass (a) work freedom, (b) warranty end and unemployment and (c) it will just benefit the famous players (consecrated). For the professionals and juniors the end of the pass means
}

work freedom, for the juvenile ones it represents benefits just for the famous players.

K ey-words: sociology of the work, sociology of the soccer, flexibility

\section{R eferências}

ARAÚ J, R. B. de. Os gênios da pelota: um estudo do futebol como profissão. Rio de Janeiro, 1980 Dissertação (M estrado) - M useu N acional/U FRJ .

DA L-RÉ, F. V. L a flexibilidad del mercado de trabajo. Teoria e ideología. In: CASTILL O, J. J. EI trabajo del futuro. Espanha: Editorial Complutense, 1999.

CORREA. Craques sem emprego. Zero H ora, 4 abr. 2002, Esportes, p. 47.

ERICSON, T. The Bosman case: effects of the abolition of the transfer fee. J ournal of Sports Economics, vol. 1, n. 3, A ugust 2000, p. 203-218.

FLORENZANO, J. P. Afonsinho e Edmundo: a rebeldia no futebol brasileiro. São Paulo: Musa Editora, 1998. [M usa A ntropologia]

FOLHA DE S. PA UL 0, 12/9/1996.

GIULIA NOTTI, R. Sociologia do futebol: dimensões históricas e socioculturais do esporte das multidões. São Paulo: N ova A lexandria, 2002.

HELAL, R. Passes e impasses: futebol e cultura de massa no B rasil. Petrópolis: Vozes, 1997.

J ORNAL DO BRASIL, 15/9/1996.

JORNAL DA TA RDE, 28/12/1995.

M A RTIN , S. Redes sociais eflexibilidade do trabalho: uma análise comparativa. Revista Latoniamericana de Estúdios D el Trabajo. A no 3, número 6, 1997, p. 9-38.

NASCIMENTO, R. P.; SEGRE, L. M . Flexibilidade produtiva $x$ flexibilidade das relações de trabalho: uma análise do setor automobilístico brasileiro. In: ENCONTRO ANUAL DA ANPOCS, 26, 2002, Caxambu/M G. Anais... Caxambu/M G, 2002.

PIM ENTA, C. A . M . Novos processos de formação de jogadores de futebol e fenômeno das 'escolinhas': uma análise crítica do possível. In: A LA BA RCES, Pablo (Org.). Peligro de gol: estúdios sobre deporte y sociedad em A mérica L atina. Buenos A ires: Clacso, 2000. [C olección G rupos de Trabajo de Clacso, Grupo de Trabajo: Deporte y Sociedad]. PRONI, M. W. A metamorfose do futebol. Campinas/ SP: Unicamp/IE, 2000.

RODRIGUES, F.X.F. F utebol e civilização: o fim do passe e a modernização conservadora no futebol brasileiro (2001-2004). Porto A legre, 2004. Projeto deTese (D outorado em Sociologia) - PPGS/UFRGS. 
A formação do jogador de futebol no Sport Club Internacional (1997-2002). Porto A legre, 2003. Dissertação (M estrado em Sociologia) Instituto de Filosofia e Ciências Humanas, Programa dePós-Graduação em Sociologia, UFRGS.

Futebol e teoria social: uma introdução à sociologia do futebol brasileiro. Ciências Sociais Unisinos, Revista do PPGCS/CCH/Unisinos, São Leopoldo-RS, n. 160, v. 38, jan/jun 2002a.

. A sociologia das profissões e a sociologia do esporte: profissionalização e mercado de trabal ho no futebol gaúcho. In: ENCONTRO ANUAL DA ANPOCS, 26, 2002, Caxambu/M G. Anais... Caxambu/ $M G, 2002 b$.
SALERNO, M. S. Flexibilidade e organização produtiva: elementos para transformar o termo flexibilidade numa categoria analítica; elementos para análise da produção na indústria.

SAYER, A.; WA LKER, R. La nueva economia social. M adri, Espanha: M inisterio del Trabajo e Seguridad Social, 1994.

SIM M ONS, R. Implications of the B osman ruling for football transfer markets. Economic Affairs, 17 (3): 1997, p. 13-18.

ZERO HORA, 4/8/2002.

Recebido em agosto de 2004 A provado em outubro de 2004 